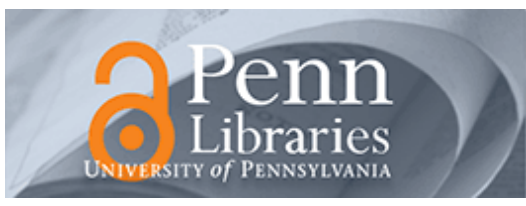

University of Pennsylvania ScholarlyCommons

$3-1-2015$

\title{
Long-Term Care Insurance: Does Experience Matter?
}

Norma B Coe

University of Pennsylvania, nbcoe@pennmedicine.upenn.edu

Meghan M Skira

Courtney Harold Van Houtven

Follow this and additional works at: https://repository.upenn.edu/mehp

Part of the Medicine and Health Sciences Commons

\section{Recommended Citation}

Coe, Norma B; Skira, Meghan M; and Van Houtven, Courtney Harold, "Long-Term Care Insurance: Does Experience Matter?" (2015). Department of Medical Ethics and Health Policy. 6.

https://repository.upenn.edu/mehp/6

This paper is posted at ScholarlyCommons. https://repository.upenn.edu/mehp/6 For more information, please contact repository@pobox.upenn.edu. 


\title{
Long-Term Care Insurance: Does Experience Matter?
}

\begin{abstract}
We examine whether long-term care (LTC) experience helps explain the low demand for long-term care insurance (LTCI). We test if expectations about future informal care receipt, expectations about inheritance receipt, and LTCI purchase decisions vary between individuals whose parents or in-laws have used LTC versus those who have not. We find parental use of a nursing home decreases expectations that one's children will provide informal care, consistent with the demonstration effect. Nursing home use by in-laws does not have the same impact, suggesting that individuals are responding to information gained about their own aging trajectory. Nursing home use by either a parent or in-law increases LTCI purchase probability by 0.8 percentage points, with no significant difference in response between parents' and in-laws' use. The estimated increase in purchase probability from experience with LTC is about half the previously estimated increase from tax policy-induced price decreases.
\end{abstract}

\section{Keywords}

Caregivers, Female, Home Care Services, Humans, Insurance, Long-Term Care, Male, Middle Aged, Models, Statistical, Nursing Homes, Parents, Risk Assessment, United States

\section{Disciplines}

Medicine and Health Sciences 
Published in final edited form as:

J Health Econ. 2015 March ; 40: 122-131. doi:10.1016/j.jhealeco.2015.01.001.

\title{
Long-Term Care Insurance: Does Experience Matter?*
}

\author{
Norma B. Coe ${ }^{\dagger}$, \\ Center for Retirement Research at Boston College, Netspar, and NBER \\ Meghan M. Skira, and \\ University of Georgia \\ Courtney Harold Van Houtven \\ Durham Veterans Affairs Medical Center and Duke University Medical Center
}

\begin{abstract}
We examine whether long-term care (LTC) experience helps explain the low demand for longterm care insurance (LTCI). We test if expectations about future informal care receipt, expectations about inheritance receipt, and LTCI purchase decisions vary between individuals whose parents or in-laws have used LTC versus those who have not. We find parental use of a nursing home decreases expectations that one's children will provide informal care, consistent with the demonstration effect. Nursing home use by in-laws does not have the same impact, suggesting that individuals are responding to information gained about their own aging trajectory. Nursing home use by either a parent or in-law increases LTCI purchase probability by 0.8 percentage points, with no significant difference in response between parents' and in-laws' use. The estimated increase in purchase probability from experience with LTC is about half the previously estimated increase from tax policy-induced price decreases.
\end{abstract}

\section{Keywords}

long-term care; insurance; informal care; expectations

\footnotetext{
*We would like to thank participants and discussants at the 2009 iHEA conference, the 2010 AcademyHealth Health Economics Workshop, the 2010 and 2012 ASHEcon conferences, the Aging Workshop at the NBER Summer Institute, Financial Capability Research Workshop, International Long-Term Care Network, and Boston College for helpful comments. We are especially thankful to Richard Frank and David Cutler for their insights. We would also like to thank the John A. Hartford Foundation Pilot Studies Grant through Duke University (Coe and Van Houtven), the Veterans Affairs Health Services Research and Development Merit Review program [MRP 05-311] (Van Houtven), and the National Institutes of Health [NIH 1R01NR13583] (Coe and Van Houtven) for funding. Any remaining errors are our own. The opinions and conclusions expressed are solely those of the authors and do not represent the opinions of Boston College, University of Georgia, University of Washington, NBER, Duke University, or the Department of Veterans Affairs

(C) 2015 Elsevier B.V. All rights reserved.

${ }^{\dagger}$ Corresponding Author. Present Address: University of Washington School of Public Health, 1959 NE Pacific Street, Seattle, WA 98195 -7660.nbcoe@uw.edu. Phone: 206-616-8530.

Publisher's Disclaimer: This is a PDF file of an unedited manuscript that has been accepted for publication. As a service to our customers we are providing this early version of the manuscript. The manuscript will undergo copyediting, typesetting, and review of the resulting proof before it is published in its final citable form. Please note that during the production process errors may be discovered which could affect the content, and all legal disclaimers that apply to the journal pertain.
} 


\section{Introduction}

Long-term care (LTC) is one of the largest financial risks facing the elderly today, yet very few people-13 percent of current 65 year olds-insure against the risk. This lack of insurance coverage has spurred much work that tries to explain this phenomenon (Finkelstein et al., 2005; Finkelstein and McGarry, 2006; Brown and Finkelstein, 2007; Brown et al., 2007; Brown and Finkelstein, 2008). It has also spurred public policy into action, with 24 states and the District of Columbia offering tax breaks for private long-term care insurance (LTCI) purchases as of 2008 (Goda, 2011). These policy changes, however, have not led to a widespread increase in coverage (Wiener et al., 2000; Meiners, 2001; Courtemanche and He, 2009; Goda, 2011). The Patient Protection and Affordable Care Act also included a now-defunct program, the Community Living and Supported Services (CLASS) Act, which would have created a new government-run LTCI pool.

In other domains of catastrophic insurance, studies have shown that after individuals experience the insurable risk, they are more likely to purchase insurance against that risk in the future (Kunreuther et al., 1978; Kunreuther, 1996; McCall et al., 1998; Browne and Hoyt, 2000; Gallagher, 2014). This response could be explained by behavioral heuristics, such as an increase in the salience of the risk, or by an increase in information about the insurable risk.

In the LTCI context, lack of experience with LTC could help explain the low demand for insurance. Experience could help overcome behavioral biases since people tend to dislike and delay discussions about becoming frail and needing assistance (Sperber et al., forthcoming). In addition, experience could fill several potential information gaps in the LTCI context: the likely need for LTC; the expense entailed in getting such care; the gaps in one's existing insurance coverage for LTC; or, one's family's willingness to provide informal care. Any of these sources of incomplete information would lead to lower than expected LTCI purchases. Previous research has provided evidence of incomplete information in at least two of these domains. Bacon et al. (1989), Pauly (1990), and AARP (2006) report that most elderly believe that LTC expenses are covered by Medicare. Further, AARP (2006) found considerable underestimation of the costs of nursing home care among individuals age 45 and older. While Brown and Finkelstein (2009) highlight limited consumer understanding of both the insurance product and the expenditure risk as one of the top five reasons for low LTCI demand, there has been no empirical testing, to our knowledge, of the extent to which lack of information depresses LTCI purchase in the United States. ${ }^{1}$

To evaluate the role experience may play in LTC and LTCI decisions, we exploit variation between individuals who have someone close to them-a parent or in-law-who needs and uses LTC and those who do not. ${ }^{2}$ Individuals who have parents or in-laws who use LTC may be more aware of the risks and costs. This paper examines how parents' and in-laws' use of LTC impacts an adult child's LTCI purchase decisions. Although we cannot

\footnotetext{
${ }_{1}$ Zhou-Richter et al. (2010) assess the role of information among adult children on the demand for LTCI for their parents in Germany. ${ }^{2}$ While LTC can encompass many types of care arrangements, in the empirical framework, due to data limitations, we limit the term to only mean two types - informal care from children and nursing home care.
} 
completely disentangle whether the effects are driven by a change in information or behavioral economics explanations, we exploit variation in the person who needed care (parent or in-law), the type of care used (nursing home or informal care), and the person who provided informal care (the adult child him or herself or a sibling) to discern which explanations may be at play. We also analyze the mechanisms underlying any resulting change in LTCI holding by examining how expectations about the future change after a parent or in-law uses LTC. In particular, we analyze how a parent or in-law's use of LTC impacts an adult child's expectations about informal care from children and inheritance receipt.

The rest of the paper is as follows: Section 2 describes how experience with LTC via parents' or in-laws' use can affect expectations and LTCI purchase decisions. Section 3 discusses the data and the sample in detail. Section 4 presents our empirical strategy. Section 5 presents the results, in which we examine the impact of parents' and in-laws' LTC use on the adult child's expectations about informal care and inheritance receipt, and on the purchase of LTCI, controlling for these expectations. Section 6 concludes that experience does matter in the decision to purchase LTCI. While the experience effect is slightly smaller than that of other policies tried, such as decreasing the Medicaid asset limits (Brown et al., 2007) or the recent tax credits and partnership programs (Goda, 2011), it does not have the same associated costs to the federal or state budget.

\section{How Experience Can Affect Expectations}

In the specific domain of risk perception and insurance, previous work has shown that individuals who experience the insurable risk are more likely to purchase insurance against that risk in the future. Kunreuther et al. (1978) find that individuals who experienced property damage in a prior natural disaster are more likely to purchase flood insurance. Similarly, flood insurance purchases increase in areas that experienced a recent flood (Browne and Hoyt, 2000; Gallagher, 2014). Palm et al. (1990) found an increase in the perceived need for earthquake insurance after the Loma Prieta earthquake, and Kunreuther (1996) finds an increase in the demand for insurance following earthquakes more generally. Coe et al. (2014) find an increase in the stated demand for disability insurance among individuals who are informed about disability risks.

In the LTC literature, some studies have explored how knowledge about LTC or individual health risks impact LTCI demand behavior. For example, McCall et al. (1998) find that individuals who have a family member or friend that needs LTC are more likely to purchase LTCI, and Zhou-Richter et al. (2010) find that German adult children are more likely to want to buy LTCI for their parents after being informed about the population average risks and costs of LTC. Brown et al. (2012) find that individuals' beliefs about the likelihood of not being able to live independently due to health problems were strongly correlated with LTCI coverage in the RAND American Life Panel. Meier (1999) formulates a theoretical model that shows individuals might wait to purchase LTCI to obtain more information about their own probability of becoming disabled as well as the costs of disability and associated care. Our paper contributes to this literature by examining how actual experience with LTC via a parent or in-law's use of nursing home or informal care impacts LTCI purchase 
behavior, exploiting variation in the relationship to the care recipient, type of care received, and who provided care.

Disentangling why experience with LTC matters in forming expectations and LTCI purchase decisions is often difficult with secondary data, but important in order to make policy recommendations. We explore three potential explanations below: (1) rational updating; (2) overcoming inertia and increasing salience; and, (3) overreaction to risks.

\subsection{Rational Updating}

The rational expectations model assumes that individuals form expectations using all available information and make optimal decisions that are based on (and consistent with) these expectations. When new information is learned, expectations about the future are updated, typically assumed in a Bayesian manner. The rational expectations model is consistent with the self-regulation model (Leventhal et al., 1992). The self-regulation model posits that individual understanding of disease is based on the individual's rationalizations about its causes, consequences, timeline, trajectory, prognosis, and their ability to control, treat, and prevent the illness. Individual understanding is informed by beliefs, experiences, family, friends, health care practitioners, and the media. Importantly, both positive and negative experiences or information can alter one's beliefs, coping strategies, and behavior.

The rational expectations model posits that LTC use by parents and parent-in-laws (hereafter, the $G_{1}$ generation) could impact one's knowledge of LTC risks and costs. Under this framework, we hypothesize that LTC use by the $G_{1}$ generation will have an information spillover effect and change the insurance status of their adult children. If individuals are already fully-informed about the risks they face and their associated costs, then LTC use by parents or in-laws will have no effect on their own expectations about future use or their financing plan. However, if individuals learn during their parents' or in-laws' LTC spell, expectations about future care use, lifetime income, and preferences for different types of care delivery may evolve, and the decision to purchase LTCI to prepare financially for these future needs may change.

We try to disentangle the type of information that is learned through the $G_{1}$ generation's use of LTC by exploiting across-family variation in who provides care, who receives care, and the type of care received. For example, helping or watching anyone navigate the LTC system will make one aware of the complexities they may face during their own aging process. Thus, information about the aging process and the costs associated with care are revealed if any individual in the $G_{1}$ generation uses any type of LTC. Additional information can be learned as outlined below.

- Relationship to care recipient: Genetic information is revealed through a health decline of a parent, but not an in-law. Because of the common genetic link, a parent's health decline may differentially influence an adult child's expected need for future LTC compared to an in-law's health decline.

- Type of care received: Whether a parent or in-law receives formal or informal care could impact an adult child's expectations or preferences about his or her own future care needs. The type of care received may provide information about the 
costs of care, the willingness of family to provide informal care, and the ability to meet LTC needs in an informal setting.

- Provision of care: As a result of providing informal care to a member of the $G_{1}$ generation, an individual may experience and learn about caregiver burden, which has many definitions in the gerontology literature (Zarit et al., 1980) or conversely, caregiver gain, such as role satisfaction (Tarlow et al., 2004), improved relationships with a parent (Roth et al., 2005), and the knowledge that one has fulfilled a familial duty (Van Houtven and Norton, 2004). Providing care to a parent or in-law may also provide a signal that an adult child expects his or her own children to do the same (i.e. the demonstration effect) (Stark, 1995; Cox and Stark, 2005). We hypothesize that an individual who provides informal care will learn more about this aspect of LTC than non-care providing adult children.

One complicating factor is that parents' or in-laws' use of LTC might impact one's lifetime income expectations through changing the size or the probability of receiving a bequest; thus, we also examine how expectations about inheritance receipt vary with LTC use in the $G_{1}$ generation. For example, a $G_{1}$ member receiving informal care might change expectations about who gets the bequest if the exchange motive is operative (Bernheim et al., 1985; Norton and Van Houtven, 2006), while formal care use may impact the expected size of the bequest, particularly if such care is paid out-of-pocket.

Further, we examine whether there are direct or indirect effects of the $G_{1}$ generation's use of LTC on how adult children plan to pay for their future care needs by analyzing their decision to purchase private LTCI. The hypothesized changes in the perceived need for insurance described above are consistent with Bayesian updating within a rational expectations framework (Viscusi, 1991). In other words, individuals gain new information from the $G_{1}$ generation's use of LTC and update their own expectations, which could result in a change in behavior in the form of purchasing LTCI.

\subsection{Overcoming Inertia and Increasing Salience}

Changes in expectations and LTCI purchase decisions among individuals with more experience with the insurable risk may also be consistent with models proposed in behavioral economics, based on the psychology literature. Two likely concepts at play in the LTC and LTCI context are inertia and salience.

- Inertia: When faced with the difficult calculation of determining whether and how much LTCI is needed, individuals may simply follow the status quo from a previous decision or avoid making a decision altogether. In this case, the status quo is non-purchase, and could lead to lower levels of insurance rates than predicted to be optimal from a rational expectations standpoint. Having someone in the $G_{1}$ generation use LTC may be a precipitating event to end the inertia.

- Salience and availability bias: "Salience refers to the phenomenon that when one's attention is differentially directed to one portion of the environment rather than to others, the information contained in that portion will receive disproportionate weighting in subsequent judgments" (Taylor and Thompson, 1982). Having 
someone in the $G_{1}$ generation use LTC may increase the salience of LTC and LTCI decisions for the adult child. The behavioral economics literature has noted that salient risks (even low-probability ones) are often given excessive weight and result in excessive reactions by individuals. Closely related, availability bias means individuals base the probability of an event on the ease with which instances of the event can be brought to mind (Tversky and Kahneman, 1974). Thus, changes in expectations and LTCI purchase in response to LTC use by the $G_{1}$ generation may reflect adult children putting excessive weight on LTC risks because they are salient or can be brought to mind easily, rather than a rational updating of the information set.

\subsection{Changing Risk Perception}

Kahneman and Tversky (1979) observe that people have "limited ability to comprehend and evaluate extreme probabilities." Indeed, the literature has found that individuals tend to overestimate low-probability events. Coe and Webb (2009) suggest that people tend to overestimate their probability of receiving an inheritance; however, previous work such as Lindrooth et al. (2000) and Taylor et al. (2005) suggests that average nursing home utilization predictions from individuals in the early years of the AHEAD data are fairly accurate compared with their actual nursing home usage 5 to 7 years later. Another phenomenon concerning probability perception is the tendency to overreact to fearsome risks and overestimate their frequency (Sunstein and Zeckhauser, 2011). Thus, changes in expectations and LTCI purchase following LTC use by the $G_{1}$ generation may capture adult children excessively reacting to LTC risks.

It is difficult to separately identify the mechanisms underlying behavior changes following experience with LTC using secondary data sources that do not specifically ask why individuals changed their expectations or decision to purchase LTCI (or without a full parameterization of the decision-making model). However, by exploiting variation in the relationship to the care recipient, the type of care received, and who provided care, we might take some steps to disentangle the different explanations. For example, within a married household with shared decision-making, it is difficult to use the salience argument to explain large differential responses to in-laws using LTC and parents using LTC. We generally discuss our findings within the context of the rational expectations and Bayesian learning framework, but we acknowledge that for the most part, we cannot completely rule out or disentangle the role of the behavioral tendencies and non-learning responses outlined above.

\section{Data}

We use data from the 1998 through 2006 waves of the Health and Retirement Study (HRS). In 1992, the HRS sampled the non-institutionalized 51 to 61 year old U.S. population, and respondents have been followed every two years. We limit the years of data due to question differences across years. We start with the 1998 wave due to the inconsistent definition of LTCI in the survey and other key variables prior (Finkelstein and McGarry, 2006), and end in 2006 due to the lack of questions about inheritance expectations in later years. 


\subsection{Sample}

We create a respondent-level dataset consisting of respondents from the original HRS cohort and their spouses. We limit our analysis to individuals over the age of 50. Given we are interested in expectations about informal care from children, an individual has to have at least one living child to be included in the sample. Since we are interested in LTCI purchase, an individual must not have LTCI in the prior survey wave and must be able to pass the LTCI underwriting screening as of the prior wave (i.e. no IADLs or ADLs and no recent strokes). ${ }^{3}{ }^{4}$ Table A1 in the Appendix details our sample restrictions. Our final estimation samples consists of 26,979 person-wave observations, representing 8,349 unique individuals.

\subsection{Variables}

First, we analyze how $G_{1}$ LTC use impacts expectations about informal care and inheritance receipt. Regarding future informal care expectations, the HRS asks, "Suppose in the future, you needed help with basic personal care activities like eating or dressing. Do you have relatives or friends (besides your [husband/wife/partner]) who would be willing and able to help you over a long period of time?" If the respondent says yes, he or she is asked, "What is the relationship to you of that person or persons?" Respondents are allowed to indicate multiple options from among a variety of people listed. If respondents include "child/childin-law" in the follow-up, we code them as expecting children to provide informal care in the future.

Having a parent use LTC could impact expectations about future inheritance receipt (either the amount or the likelihood of receiving one), and consequently impact one's expectations about lifetime wealth. Such changes could subsequently impact the financial planning that he or she may need to undertake to handle LTC expenses in the future, including the choice between self-insuring and having private LTCI. The HRS asks, "What are the chances you will receive an inheritance during the next 10 years?" Individuals can respond with a probability between 0 and 100, which we rescale to be between 0 and 1.5

Second, we test the influence of the $G_{1}$ generation's use of LTC on LTCI purchase, controlling for the adult child's expectations. Regarding LTCI, the HRS asks, "Not including government programs, do you now have any long term care insurance which specifically covers nursing home care for a year or more or any part of personal or medical care in your home?" Individuals can respond yes or no. We define purchase to mean an individual answered yes to the LTCI question in the current survey wave but answered no in the prior wave. As mentioned earlier, we examine purchase only among individuals healthy enough to pass the underwriting screening as of the prior survey wave.

\footnotetext{
${ }^{3}$ IADLs are instrumental activities of daily living which include food preparation, housekeeping, managing finances, taking medication, among other activities. ADLs are activities of daily living, which including bathing, dressing, eating, toileting, and transferring (walking).

${ }^{4}$ We focus on LTCI purchase and not LTCI coverage to ensure the potential information gained from $G_{1}$ LTC use occurs before the LTCI purchase.

${ }^{5}$ In 2006, the question wording changed to "What are the chances that you (or your [husband/wife/partner]) will receive an inheritance during the next 10 years?"
} 
The primary explanatory measures of interest are whether parents and in-laws received LTC and which type of care. We can identify informal care and nursing home care use of the $G_{1}$ generation. The HRS asks respondents where each of their parents and in-laws currently lives, with one of the possible responses being in a nursing home. In addition, if a parent or in-law has passed away since the prior survey wave, the HRS asks respondents whether that parent or in-law ever lived in a nursing home. We categorize parents or in-laws who currently live or ever lived in a nursing home as having utilized nursing home care. ${ }^{6}$

In order to measure informal care provided to the $G_{1}$ generation, the HRS asks each respondent if he or she and his or her spouse spent a total of 100 or more hours in the last two years helping each parent or in-law with "basic personal activities like dressing, eating, and bathing." The survey then asks who was helped and how many hours of care the respondent, and separately his or her spouse provided. The survey also asks which siblings and sibling in-laws, if any, provide help with these tasks. ${ }^{7}$

\section{Empirical Strategy}

In order to examine the effect of LTC use of the $G_{1}$ generation on the adult child's expectations about informal care provision from his or her children, we estimate the following equation using a logit model:

$$
\operatorname{Pr}\left(\text { ExpectIC }_{i t}=1\right)=f\left(\alpha_{0}+\alpha_{1} A_{i t}+\alpha_{2} H_{i t}+\alpha_{3} I C_{i t}+\alpha_{4} Z_{i t}+\alpha_{5} F_{i t}+\alpha_{6} w_{t}+\varepsilon_{i t}\right),
$$

where ExpectIC $C_{t}$ is an indicator variable for whether individual $i$ at time $t$ expects that his or her children will be willing to provide informal care in the future.

$A_{i t}$ is a vector of LTC received by parents and in-laws, measuring if LTC was ever provided before or during time $t$. In our estimation, we consider three separate vectors of LTC received by the $G_{1}$ generation to delineate across types of information provided: (1) Any parent or in-law receives any type of LTC; (2) Any parent or in-law receives nursing home care versus any parent or in-law receives informal care; (3) Own parent uses nursing home care; own parent receives informal care from the respondent; own parent receives informal care from the respondent's siblings, and the three in-law correlates. $H_{i t}$ is a vector of the adult child's health information, included to capture risk factors for future LTC needs. This vector includes the number of ADLs, the number of IADLs, an indicator for a low cognition score, the number of chronic conditions, an indicator for incontinence problems, and indicators for whether the adult child has previously used nursing home, home health, or informal care in the past two years. $I C_{i t}$ represents the potential informal care network available to the respondent (besides a spouse) including the number of male and female children, the number of living siblings, the number of co-resident children, and the number of children living within 10 miles (excluding co-resident children). The individual-level characteristics included in the vector $Z_{i t}$ are age, age squared, gender, race, and education

\footnotetext{
${ }^{6}$ The HRS does not contain information about formal home health care use of parents or in-laws. As a result, unfortunately, we cannot analyze how $G_{1}$ generation use of formal home health care affects expectations or LTCI purchase.

${ }^{7} \mathrm{We}$ do not include help with chores, errands, or transportation in our definition of informal care in order to keep the definition consistent between respondents and siblings, for whom we only know about personal care provision.
} 
categories (less than high school, high school, and at least some college) for the respondent and his or her mother and father. We also include an indicator for being married, being divorced, and an interaction term between gender and divorced, as well as an indicator for whether all parents and in-laws are deceased. $F_{i t}$ is a vector of financial information. This includes annual financial wealth quartiles, annual housing wealth quartiles, whether the respondent and his or her spouse have assets in a trust, whether the respondent has a will that benefits his or her children, and whether the children hold the deed to the house. Last, we include survey wave indicators, $w_{t}$. The standard errors are clustered at the individual level to account for repeated observations.

To analyze the effect of LTC use of the $G_{1}$ generation on the adult child's reported probability of receiving an inheritance, we estimate the following fractional logit model:

$$
E\left(\text { ExpectInher }_{i t}\right)=\frac{\exp \left(\mathbf{X}_{i t} \beta\right)}{1+\exp \left(\mathbf{X}_{i t} \beta\right)}
$$

where ExpectInher $r_{i t}$ is individual $i$ 's self-reported probability at time $t$ of receiving an inheritance, taking on values from 0 to 1 inclusive, and

$$
\mathbf{X}_{i t} \beta=\beta_{0}+\beta_{1} A_{i t}+\beta_{2} H_{i t}+\beta_{3} I C_{i t}+\beta_{4} Z_{i t}+\beta_{5} F_{i t}+\beta_{6} w_{t} .
$$

$A_{i t}, H_{i t}, I C_{i t}, Z_{i}, F_{i t}$, and $w_{t}$ are as defined above. The fractional logit model developed by Papke and Wooldridge (1996) accounts for the fact that the dependent variable is a proportion and can take on values of 0 or 1 .

We then examine the impact of the $G_{1}$ generation receiving LTC on LTCI purchase, adding expectations about future informal care and inheritance receipt to the regression in order to disentangle the direct effect of experience on LTCI purchase from the indirect effects that operate via changes in expectations. Therefore, we estimate the following logit model:

$$
\begin{gathered}
\operatorname{Pr}\left(\operatorname{LTCI}_{i t}=1\right)= \\
f\left(\delta_{0}+\delta_{1} A_{i t}+\delta_{2} \text { ExpectIC }_{i t}+\delta_{3} \text { ExpectInher }_{i t}+\delta_{4} H_{i t}+\delta_{5} I C_{i t}+\delta_{6} Z_{i t}+\delta_{7} F_{i t}+\delta_{8} w_{t}+\varepsilon_{i t}\right),
\end{gathered}
$$

where $L T C I_{i t}$ is an indicator variable for reporting having an LTCI policy in period $t$ conditional on not having one in period $t-1 . A_{i t}$, ExpectIC $_{i t}$, ExpectInher $_{i t}, H_{i}, I C_{i t}, Z_{i t}, F_{i t}$, and $w_{t}$ are as defined above.

\section{Results}

Table 1 presents the descriptive statistics from our estimation sample. About 50 percent of the sample expect their children to provide informal care in the future. The average expected probability of receiving an inheritance in the future is 15 percent. Approximately 5 percent of the sample ever purchases LTCI during the period we consider. Almost 70 percent had some interaction with the LTC system via their parents or in-laws. About 52 percent of the $G_{1}$ generation used a nursing home while 42 percent used informal care (these are not mutually exclusive options). 
The average age in the sample is almost 65 . There are slightly more females than males, and 74 percent of the sample is married. Very few of the respondents have already used LTC themselves-likely reflecting the sample selection criteria of being able pass the LTCI underwriting screening. Not even 1 percent of the sample has used informal or nursing home care, but almost 7 percent has used formal home health care in some capacity. ${ }^{8}$

On average, the sample has many potential informal care providers. As mentioned earlier, almost three-quarters of the sample is married, and individuals have almost 3 living siblings, 2 sons, and 2 daughters, on average. In addition, one of the respondent's children lives within 10 miles, on average.

Table 2 presents the marginal effects and standard errors from the logit model estimating the impact of $G_{1}$ LTC use on whether an individual expects his or her children will provide informal care in the future. ${ }^{9}$ Column 1 presents the marginal effects from the model estimating the effect of any $G_{1}$ member using any type of LTC. Column 2 breaks down $G_{1}$ LTC use between nursing home and informal care. Column 3 presents the results when $G_{1}$ LTC use is broken down into six categories: parent uses nursing home care, respondent provides informal care to parent, respondent's sibling provides informal care to parent, and the three in-law correlates.

We find evidence that an individual's expectations about informal care from their children or children-in-law are impacted by nursing home use of the $G_{1}$ generation, and this effect is driven by the respondent's own parent's nursing home use. If the respondent's parent uses a nursing home, he or she is 2.7 percentage points less likely to expect his or her child will provide care in the future. This result is consistent with the demonstration effect. If an individual's parent uses a nursing home, that individual has not signaled that he or she expects or prefers to receive informal care from his or her children, which may decrease expectations about future informal care receipt. This result is also consistent with some of the behavioral responses outlined above. For example, if the parent's use of nursing home care is salient or can be brought to mind easily, individuals might give disproportionate weight to the probability of using nursing home care in the future, and consequently report that they do not expect informal care. However, it is harder to use salience or risk perception as an explanation for the large difference in effects of in-law versus parental use of nursing home care on informal care expectations.

Next, we explore the effect of $G_{1}$ LTC use on the self-reported probability of receiving an inheritance. Marginal effects and standard errors from the fractional logit model are presented in Table 3. We find that the direction of the effect depends on the type of care the $G_{1}$ generation utilized. After an individual's parent uses nursing home care, he or she decreases expectations about future inheritance receipt by 2.9 percentage points. If a respondent provides informal care to his or her own parent, he or she increases inheritance

\footnotetext{
${ }^{8}$ While controlling for prior LTC use seems logical when estimating expectations about future informal care, using LTC oneself likely informs individuals about LTC costs and probabilities above and beyond the information set learned from the $G_{1}$ generation receiving LTC. We have rerun our baseline equations eliminating those with their own experience with LTC, and we find quantitatively similar results which we discuss later.

${ }^{9}$ The coefficients and marginal effects of the control variables are largely as expected. Full results are available upon request.
} 
expectations by 1.4 percentage points, but if a sibling-in-law provides care to the respondent's in-law, he or she decreases inheritance expectations by 1.7 percentage points. The decrease in expected inheritance receipt after a parent uses nursing home care may be explained by the child observing that there is less wealth to inherit as a result of the parent spending down to qualify for Medicaid or to pay for nursing home care out-of-pocket. The finding that informal care provided to a parent by the respondent increases the likelihood of receiving an inheritance, while sibling-in-law provision of informal care to an in-law decreases that likelihood suggests that individuals believe an exchange or bequest motive is operative (i.e. that individuals who provide care will be rewarded with a bequest).

We analyze the effect of LTC use among the $G_{1}$ generation on LTCI purchase, controlling for informal care and inheritance expectations, to examine if there is a direct effect of experience on LTCI purchase. Results are shown in Table 4. In Column 2, we find having a $G_{1}$ member use a nursing home increases the probability of LTCI purchase by 0.9 percentage points. In particular, having a parent use a nursing home increases the probability of LTCI purchase by 0.8 percentage points and having an in-law use a nursing home increases the probability of purchase by 0.6 percentage points, though the latter effect is marginally significant $(p=0.053$ ). Given that these effects are not statistically different from each other, our results suggest that by observing someone in the $G_{1}$ generation receive nursing home care, the adult child changes his or her financial planning strategy to handle future LTC expenses. This change might be driven by information learned about the costs of nursing home care and the lack of public insurance coverage for nursing home expenses. It is also consistent with behavioral responses. If individuals typically follow the status quo of non-purchase, seeing a $G_{1}$ member use nursing home care may be the impetus to end that inertia. It is important to note that informal care does not trigger the same response. This could be due to different information learned through informal caregiving versus nursing home care regarding formal care expenses. Further, it is suggestive that the increase in LTCI purchase probability is not only driven by an overreaction to low-probability risks.

Interestingly, we find individuals who expect their children will provide informal care for them in the future are 0.6 percentage points more likely to purchase LTCI. While this result is unexpected, it might reflect that some individuals who know or expect that their children will provide care want to avoid burdening their children as diseases progress and purchase LTCI. For example, qualitative work suggests that parents want their children to provide "support but not be burdened" should the need for LTC arise (Sperber et al., forthcoming). This result may also reflect that individuals who expect their children to provide informal care have already had discussions about future LTC alternatives and are relatively more forward-looking, leading them to purchase LTCI.

We find inheritance expectations have no significant effect on the probability of purchasing LTCI. Given the median inheritance in the U.S. is less than one year of average nursing home costs, this non-result is not surprising (Wolff and Gittleman, 2014).

Since $G_{1}$ nursing home use decreases expectations about informal care receipt, and these expectations influence LTCI purchase, we run a simple counterfactual exercise to estimate the total effect $G_{1}$ nursing home use has on LTCI purchase probability. We use the 
estimated models to predict a counterfactual case where no one had a member of the $G_{1}$ generation use a nursing home and then a separate counterfactual where everyone had a $G_{1}$ generation member who received nursing home care. ${ }^{10}$ We perform the counterfactual on the informal care and inheritance expectations equations, and then on the LTCI purchase equation accounting for the expectations as well as the direct effects of $G_{1}$ nursing home use on LTCI purchase. This counterfactual exercise suggests that having either a parent or an inlaw use nursing home care increases LTCI purchase probability by 0.7 to 0.8 percentage points. One interpretation of this finding is that most of the information learned through these experiences is about LTC more generally. This information could be about the costs of LTC, the incomplete insurance for these costs, or about general aging processes. Given that the effect is somewhat similar regardless of the relationship with the $G_{1}$ care recipient, new information about one's own genetic predisposition in the aging process may play a role but not an especially large one in the decision to purchase LTCI. Alternatively, this finding could indicate that having a $G_{1}$ member use nursing home care provides the impetus to take action and to buy LTCI. Individuals without this "reminder" may delay, possibly to the point where they no longer meet the screening criteria for coverage.

\subsection{Heterogeneity}

Brown et al. (2007) and Brown and Finkelstein (2008) highlight that Medicaid, while means-tested, provides considerable insurance coverage for LTC risks for those in the lower portion of the wealth distribution, and thus the demand for LTCI may be crowded out by public insurance. Thus, wealth may be an important source of heterogeneity in the responses to learning about LTC. To test for this heterogeneity, we reestimate the expectations and LTCI equations only on the top half of the wealth distribution. In Table 5, we present results for the more detailed breakdown of $G_{1}$ LTC use. ${ }^{11}$ We find the impact of $G_{1}$ LTC use on informal care expectations is similar to that of the baseline. While we again find that a parent using a nursing home decreases an adult child's self-reported probability of receiving an inheritance, we no longer find the respondent's provision of care to a parent or a siblingin-law's provision of care to the respondent's in-law significantly impacts that probability. Instead, we find siblings providing care to the respondent's parent increases the respondent's inheritance expectations. Individuals may believe the exchange motive is operative, but informal care provided by siblings might impact the relative size of the expected inheritance between siblings, not the probability of receiving an inheritance. ${ }^{12}$ Similar to the baseline results, nursing home care received by the respondent's parent increases the probability the respondent purchases LTCI. We also find the impact of an in-law's use of nursing home care more significantly increases the probability of purchasing LTCI compared to the baseline estimates. Seeing a parent (or in-law) use nursing home care may provide important information about the costs and insurance coverage of such care, which may be especially important for relatively wealthy individuals who are less likely to qualify for Medicaid and

\footnotetext{
${ }^{10}$ More specifically, we separately predict two counterfactual cases where no one versus everyone: (1) had a parent use nursing home care; (2) had an in-law use nursing home care.

${ }_{11}$ The results for the broader breakdowns of $G_{1}$ LTC use are available upon request.

12 It is important to note that we only observe expectations about receiving an inheritance, not about the amount of the inheritance, and thus the identity of the informal care provider may be less important for the extensive margin expectation. Previous work suggests that parents often leave the exact same amounts to children in a will, regardless of informal care provision (McGarry, 1999).
} 
more able to afford the LTCI premiums, prompting them to purchase LTCI. Interestingly, if a respondent provided informal care to an in-law, he or she has a significantly lower probability of purchasing LTCI. Providing care for an in-law might signal that the individual places heavy weight on reciprocity and familial responsibility norms, and thus, has a preference for informal care over formal care, leading to a decreased probability of LTCI purchase. Those with relatively more wealth who especially value responsibility norms and are altruistic may be more willing to self-insure against LTC in the hopes of leaving a large incidental bequest should LTC go unused. Lockwood (2013) finds bequest motives, where bequests are assumed to be luxury goods, increase savings and decrease LTCI purchases, especially for individuals in the top half of the wealth distribution.

We also explore heterogeneity in the effects by the age at which the $G_{1}$ generation member first received LTC. We create an indicator variable for the $G_{1}$ member being 80 years old or younger versus older than 80 years old when care was first received. ${ }^{13} \mathrm{We}$ interact this indicator variable with our measures of $G_{1}$ LTC use. Results are available upon request but we provide a discussion of our findings for the more detailed breakdown of $G_{1}$ LTC use below.

Overall, we find fairly consistent effects based on the age at which a parent or in-law starts receiving care. We find that if a parent was over 80 years old when he or she first received nursing home care, the adult child is 3.2 percentage points less likely to expect his or her own children will provide informal care in the future, compared to no significant effect if the parent was young. However, the effects are not statistically different from each other. Inheritance expectations decrease regardless of the age at which the $G_{1}$ member uses a nursing home or the age at which sibling-in-laws provide informal care to in-laws. These estimated effects are slightly larger for care that began when the parent was 80 years old or younger, although the difference between the effects is statistically insignificant. Intuitively, a parent who initiates LTC at a "younger" age has the potential for a longer care episode and more expenses, decreasing the wealth available to leave as a bequest. We find no significant age-related heterogeneity in the effect of parents using a nursing home on LTCI purchase decisions.

There are a few cases where we find evidence of heterogeneity of effects based on the age of LTC onset. For example, a respondent is more likely to expect an inheritance if his or her sibling provided care to an "older" parent, compared to no significant effect if the sibling provides care to a "young" parent. This finding is consistent with the idea that the expected care episode might be relatively short in duration, and thus there will be financial resources left to disperse. Regarding LTCI purchase, we find when a respondent provides informal care that started when the parent was "young," the respondent is 1.4 percentage points less likely to purchase LTCI. This finding is consistent with the idea that informal care provision to younger parents represents more commitment to informal care and thus less demand for LTCI. It is also consistent with a financial drain story-providing care to younger parents, with potentially a longer disability spell, could make individuals unable to afford LTCI.

${ }^{13}$ We selected 80 years old as the cutoff because that was the median age at which LTC began for the $G_{1}$ generation in our sample. The average age was 79.5 years old. 
Further work eliciting individual expectations about length of care spell and the financial burdens of care provision would be needed to tease out these explanations.

\subsection{Specification and Robustness Checks}

To address the concern that families with $G_{1}$ LTC use are different from families without any $G_{1}$ LTC use, we rerun the regressions only on the subsample of individuals who have someone in the $G_{1}$ generation who accessed LTC at some point. Thus, the identifying variation comes from pre- and post-G1 LTC use among LTC-using families. The results are quite robust, both quantitatively and qualitatively, to the baseline estimates. ${ }^{14}$

One may have concerns about the selection of control variables. In particular, prior LTC use of the respondent may be endogenous with respect to the expectations we consider as well as LTCI purchase, which would bias our results. We reestimate all the specifications excluding individuals who have previously used LTC themselves. ${ }^{15}$ While we still find a parent's use of nursing home care increases the individual's probability of purchasing LTCI, the marginal effect is slightly smaller and less precise than in the baseline. Overall, however, the results are robust to the exclusion of individuals who used LTC themselves.

Finally, one might be concerned about the age criteria used to select the sample. We have rerun all models restricting the sample to individuals age 65 and older, a "typical" age at which individuals may retire and begin LTC planning. ${ }^{16}$ Due to a drop in sample size, some of the effects of $G_{1}$ LTC use on expectations and LTCI purchase are less precise, but are of similar estimated size relative to the baseline results. Consistent with the baseline results, we again find a parent's nursing home use significantly decreases expectations about future informal care receipt and inheritance receipt, and increases the probability of purchasing LTCI. Results are available upon request.

\section{Conclusion}

This paper analyzes the effects of experiencing parents' and in-laws' use of LTC on an individual's expectations about informal care and inheritance receipt as well as the probability of purchasing LTCI. We find that nursing home use has the largest and most significant impact on both individual expectations and LTCI purchase decisions. We find that individuals are more likely to purchase LTCI if a close relative has used a nursing home, even after controlling for expectations about the future. Supporting the evidence of Medicaid crowd-out highlighted in Brown et al. (2007) and Brown and Finkelstein (2008), the estimated effects of LTC experience are stronger among the wealthier half of the sample, who are less likely to be affected by Medicaid coverage for nursing homes.

\footnotetext{
${ }^{14}$ The results are available upon request.

15 The results are available upon request.

16 One benefit of this sample age restriction is that we can use the HRS question concerning individuals' assessment of their probability of entering a nursing home in the next 5 years, which is only consistently asked across waves to individuals age 65 and over. We chose not to include this expectation in our baseline analysis because it would have imposed a substantial sample restriction and severely limited the age ranges for which we could analyze LTCI purchase behavior. However, when we repeat our analysis on the older individuals, with or without the nursing home entry expectation as an outcome and as an expectation that could affect LTCI purchase, we find qualitatively similar results to those of the baseline, although we lose some significance due to the drop in sample size.
} 
Our findings are interesting in light of the standard asymmetric information (AI) model and work by Finkelstein and McGarry (2006) on LTCI. Standard AI models predict that in equilibrium there will be a positive correlation between the amount of insurance purchased and the occurrence of the risky event (Chiappori and Salanie, 2000; Dionne et al., 2001; Chiappori et al., 2006). Finkelstein and McGarry (2006) posit that two types of individuals may lead to violations in the standard model: individuals with private information that they are a higher risk than the insurance company expects (for example, due to unobserved health status); or individuals with private information that have a strong taste for insurance and are lower risk than the insurance company expects (i.e. risk averse individuals). Our analysis suggests that LTC use of parents and in-laws, particularly nursing home care, makes individuals change their expectations about their own use of LTC in the future, as well as the uptake of LTCI. This type of information has not been explicitly considered in the AI models.

Overall, the total estimated effect of a parent using a nursing home on LTCI purchase is about half of the previously estimated effects of potential policy levers, such as having all states lower their Medicaid asset test to the federal minimum (Brown et al., 2007), or the effects of state tax deductions on LTCI holding (Goda, 2011). However, unlike these policies, providing the information or the impetus to action that is equivalent to having a parent or in-law use a nursing home has no direct impact on state or federal revenues. Since the CLASS Act has failed, policymakers could look to information campaigns as potentially cheaper interventions if increasing LTCI coverage is a priority.

\section{Appendix}

\section{Table A1}

Sample Restrictions

\begin{tabular}{lc}
\hline & \# Person-wave observations \\
\hline All HRS respondents in waves 1998-2006 & 48,404 \\
Age 50 and over & 47,241 \\
Has living children & 44,745 \\
Informal care and inheritance expectations questions answered & 37,298 \\
Did not have LTCI in the prior wave & 32,001 \\
Healthy enough to pass underwriting screening as of the prior wave & 27,066 \\
LTCI question answered & 27,066 \\
Full set of control variables available & 26,979 \\
\hline
\end{tabular}

\section{References}

AARP. The Costs of Long-term Care: Public Perception Versus Reality in 2006. Washington, DC: 2006.

Bacon PW, Gitman LJ, Ahmad K, Ainina MF. Long-term Catastrophic Care: A Financial Planning Perspective. Journal of Risk and Insurance. 1989; 56:146-154.

Bernheim BD, Shleifer A, Summers LH. The Strategic Bequest Motive. Journal of Political Economy. 1985; 93:1045-76. 
Brown, JR.; Coe, NB.; Finkelstein, A. Tax Policy and the Economy. Vol. 21. MIT Press; 2007. Medicaid Crowd-out of Private Long-term Care Insurance Demand: Evidence from the Health and Retirement Survey; p. 1-34.

Brown JR, Finkelstein A. Why is the Market for Long-term Care Insurance So Small? Journal of Public Economics. 2007; 91:1967-1991.

Brown JR, Finkelstein A. The Interaction of Public and Private Insurance: Medicaid and the LongTerm Care Insurance Market. American Economic Review. 2008; 98:1083-1102.

Brown JR, Finkelstein A. The Private Market for Long-Term Care Insurance in the United States: A Review of the Evidence. Journal of Risk and Insurance. 2009; 76:5-29. [PubMed: 20046809]

Brown JR, Goda GS, McGarry K. Long-term Care Insurance Demand Limited by Beliefs About Needs, Concerns About Insurers, and Care Available From Family. Health Affairs. 2012; 31:12941302. [PubMed: 22665842]

Browne MJ, Hoyt RE. The Demand for Flood Insurance: Empirical Evidence. Journal of Risk and Uncertainty. 2000; 20:291-306.

Chiappori P-A, Jullien B, Salanié B, Salanie F. Asymmetric Information in Insurance: General Testable Implications. The RAND Journal of Economics. 2006; 37:783-798.

Chiappori P-A, Salanie B. Testing for Asymmetric Information in Insurance Markets. Journal of Political Economy. 2000; 108:56-78.

Coe, NB.; Belbase, A.; Wu, A. Overcoming Barriers to Life Insurance Coverage: A Behavioral Approach. Mimeo; 2014.

Coe NB, Webb A. Actual and Anticipated Inheritance Receipts. Center for Retirement Research Working Paper. 2009; 32

Courtemanche C, He D. Tax Incentives and the Decision to Purchase Long-term Care Insurance. Journal of Public Economics. 2009; 93:296-310.

Cox D, Stark O. On the Demand for Grandchildren: Tied Transfers and the Demonstration Effect. Journal of Public Economics. 2005; 89:1665-1697.

Dionne G, Gouriéroux C, Vanasse C. Testing for Evidence of Adverse Selection in the Automobile Insurance Market: A Comment. Journal of Political Economy. 2001; 109:444-453.

Finkelstein A, McGarry K. Multiple Dimensions of Private Information: Evidence from the Long-term Care Insurance Market. American Economic Review. 2006; 96:938-958. [PubMed: 21253439]

Finkelstein A, McGarry K, Sufi A. Dynamic Inefficiencies in Insurance Markets: Evidence from Long-Term Care Insurance. American Economic Review. 2005; 95:224-228.

Gallagher J. Learning about an Infrequent Event: Evidence from Flood Insurance Take-Up in the United States. American Economic Journal: Applied Economics. 2014; 6:206-233.

Goda GS. The Impact of State Tax Subsidies for Private Long-term Care Insurance on Coverage and Medicaid Expenditures. Journal of Public Economics. 2011; 95:744-757.

Kahneman D, Tversky A. Prospect Theory: An Analysis of Decision Under Risk. Econometrica. 1979; 47:263-291.

Kunreuther H. Mitigating Disaster Losses Through Insurance. Journal of Risk and Uncertainty. 1996; 12:171-187.

Kunreuther, H.; Ginsberg, R.; Miller, L.; Sagi, P.; Slovic, P.; Borkan, B.; Katz, N. Disaster Insurance Protection: Public Policy Lessons. New York: Wiley; 1978.

Leventhal H, Diefenbach M, Leventhal EA. Illness Cognition: Using Common Sense to Understand Treatment Adherence and Affect Cognition Interactions. Cognitive Therapy and Research. 1992; 16:143-163.

Lindrooth RC, Hoerger TJ, Norton EC. Expectations Among the Elderly about Nursing Home Entry. Health Services Research. 2000; 35:1181-1202. [PubMed: 11130816]

Lockwood LM. Incidental Bequests: Bequest Motives and the Choice to Self-Insure Late-Life Risks. 2013 Working Paper.

McCall N, Mangle S, Bauer E, Knickman J. Factors Important in the Purchase of Partnership Longterm Care Insurance. Health Services Research. 1998; 33:187. [PubMed: 9618667]

McGarry K. Inter vivos Transfers and Intended Bequests. Journal of Public Economics. 1999; 73:321351.

$J$ Health Econ. Author manuscript; available in PMC 2016 March 01. 
Meier V. Why the Young Do Not Buy Long-term Care Insurance. Journal of Risk and Uncertainty. 1999; 18:83-98.

Meiners, MR. Reflections of a Partnership Insider on Long Term Care Financing. In: McCall, N., editor. Who Will Pay for Long Term Care: Insights from the Partnership Programs. 2001. p. 289-299.

Norton EC, Van Houtven CH. Inter-vivos Transfers and Exchange. Southern Economic Journal. 2006; 73:157-172.

Palm, RI.; Hodgson, ME.; Blanchard, RD.; Lyons, DI. Earthquake Insurance in California: Environmental Policy and Individual Decision-Making. Boulder, Co: Westview Press; 1990.

Papke LE, Wooldridge JM. Econometric Methods for Fractional Response Variables With an Application to 401 (K) Plan Participation Rates. Journal of Applied Econometrics. 1996; 11:619632.

Pauly MV. The Rational Nonpurchase of Long-term-Care Insurance. Journal of Political Economy. 1990; 98:153-168.

Roth DL, Mittelman MS, Clay OJ, Madan A, Haley WE. Changes in Social Support as Mediators of the Impact of a Psychosocial Intervention for Spouse Caregivers of Persons with Alzheimer's Disease. Psychology and Aging. 2005; 20:634-644. [PubMed: 16420138]

Sperber NR, Voils CI, Coe NB, Konetzka RT, Boles J, Van Houtven CH. How Can Adult Children Influence Parents' Long-Term Care Insurance Purchase Decisions? The Gerontologist. forthcoming.

Stark, O. Altruism and Beyond: An Economic Analysis of Transfers and Exchanges Within Families and Groups. Cambridge, UK: Cambridge University Press; 1995.

Sunstein CR, Zeckhauser R. Overreaction to Fearsome Risks. Environmental and Resource Economics. 2011; 48:435-449.

Tarlow BJ, Wisniewski SR, Belle SH, Rubert M, Ory MG, Gallagher-Thompson D. Positive Aspects of Caregiving Contributions of the REACH Project to the Development of New Measures for Alzheimer's Caregiving. Research on Aging. 2004; 26:429-453.

Taylor DH, Osterman J, Will Acuff S, Østbye T. Do Seniors Understand Their Risk of Moving to a Nursing Home? Health Services Research. 2005; 40:811-828. [PubMed: 15960692]

Taylor SE, Thompson SC. Stalking the Elusive "Vividness" Effect. Psychological Review. 1982; 89:155-181.

Tversky A, Kahneman D. Judgment Under Uncertainty: Heuristics and Biases. Science. 1974; 185:1124-1131. [PubMed: 17835457]

Van Houtven CH, Norton EC. Informal Care and Health Care Use of Older Adults. Journal of Health Economics. 2004; 23:1159-1180. [PubMed: 15556241]

Viscusi, WK. Economic Theories of Decision Making Under Uncertainty: Implications for Policy Analysis. In: Weimer, D., editor. Policy Analysis and Economics. Boston, MA: Kluwer Academic Publishers; 1991. p. 85-109.

Wiener JM, Tilly J, Goldenson SM. Federal and State Initiatives to Jump Start the Market for Private Long-term Care Insurance. Elder Law Journal. 2000; 8:57-102.

Wolff EN, Gittleman M. Inheritances and the Distribution of Wealth or Whatever Happened to the Great Inheritance Boom? The Journal of Economic Inequality. 2014; 12:439-468.

Zarit SH, Reever KE, Bach-Peterson J. Relatives of the Impaired Elderly: Correlates of Feelings of Burden. The Gerontologist. 1980; 20:649-655. [PubMed: 7203086]

Zhou-Richter T, Browne MJ, Gründl H. Don't They Care? Or, Are They Just Unaware? Risk Perception and the Demand for Long-Term Care Insurance. Journal of Risk and Insurance. 2010; 77:715-747. 
Table 1

Descriptive Statistics

\begin{tabular}{|c|c|}
\hline Variable & Average \\
\hline \multicolumn{2}{|l|}{ Outcomes: Expectations and LTCI } \\
\hline Expect informal care from children/children-in-law & 0.505 \\
\hline Probability of receiving inheritance & 0.151 \\
\hline Purchased LTCI & 0.055 \\
\hline \multicolumn{2}{|l|}{$G_{1}$ Long-Term Care Measures } \\
\hline Any $G_{1}$ received LTC & 0.689 \\
\hline Any $G_{1}$ received nursing home care & 0.520 \\
\hline Any $G_{1}$ received informal care & 0.422 \\
\hline Parent used nursing home care & 0.343 \\
\hline In-law used nursing home care & 0.298 \\
\hline Parent received informal care from respondent & 0.156 \\
\hline Parent received informal care from respondent's sibling(s) & 0.219 \\
\hline In-law received informal care from respondent & 0.084 \\
\hline In-law received informal care from respondent's sibling(s)-in-law & 0.176 \\
\hline \multicolumn{2}{|l|}{ Health Variables } \\
\hline \# of ADLs & 0.073 \\
\hline \# of IADLs & 0.021 \\
\hline Low cognition & 0.067 \\
\hline Incontinent & 0.148 \\
\hline \# of chronic conditions & 1.504 \\
\hline Ever used informal care & 0.009 \\
\hline Ever used formal home health care & 0.067 \\
\hline Ever used nursing home care & 0.008 \\
\hline \multicolumn{2}{|l|}{ Financial Variables } \\
\hline Has a trust & 0.080 \\
\hline Has children on deed to house & 0.033 \\
\hline Has children on will & 0.488 \\
\hline \multicolumn{2}{|l|}{ Demographic Variables } \\
\hline Age & 64.713 \\
\hline Female & 0.581 \\
\hline Married & 0.736 \\
\hline Divorced & 0.123 \\
\hline Non-white & 0.148 \\
\hline \multicolumn{2}{|l|}{ Education: } \\
\hline Less than high school & 0.227 \\
\hline High school graduate & 0.372 \\
\hline Some college & 0.401 \\
\hline \multicolumn{2}{|l|}{ Mother's education: } \\
\hline Less than high school & 0.539 \\
\hline
\end{tabular}

$J$ Health Econ. Author manuscript; available in PMC 2016 March 01. 


\begin{tabular}{lc}
\hline Variable & Average \\
\hline High school graduate & 0.278 \\
Some college & 0.104 \\
Missing & 0.078 \\
Father's education: & \\
$\quad$ Less than high school & 0.553 \\
High school graduate & 0.226 \\
Some college & 0.114 \\
$\quad$ Missing & 0.107 \\
All parents and in-laws deceased & 0.548 \\
Informal Care Network Variables & \\
\# of living siblings & 2.850 \\
\# of male children & 1.850 \\
\# of female children & 1.773 \\
\# of co-resident children & 0.293 \\
\# of children within 10 miles & 0.982 \\
\hline \# of person-wave observations & 26,979 \\
\hline
\end{tabular}




\section{Table 2}

Expectations about Future Informal Care Provision by Children

\begin{tabular}{lccc}
\hline & I & II & III \\
\hline Any $G_{1}$ used LTC & $-0.0166^{*}(0.00888)$ & & \\
Any $G_{1}$ used nursing home care & & $-0.0223^{* * *}(0.00848)$ & \\
Any $G_{1}$ used informal care & $-0.00586(0.00851)$ & \\
Parent used nursing home care & & $-0.0267^{* * *}(0.00885)$ \\
In-law used nursing home care & & $-0.00378(0.00943)$ \\
R provided care to parent & & $0.0154(0.0124)$ \\
Sibling provided care to parent & & $0.00122(0.0111)$ \\
R provided care to in-law & & $-0.0197(0.0156)$ \\
Sibling-in-law provided care to R's in-law & & $0.00104(0.0118)$ \\
\hline Observations & 26,979 & 26,979 & 26,979 \\
\hline
\end{tabular}

NOTES: R denotes the HRS respondent. Marginal effects are shown and the standard errors of those marginal effects are in parentheses. Standard errors are clustered at the individual level. Significance levels:

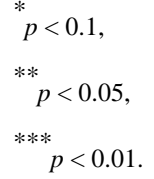


Table 3

Expectations about Future Inheritance Receipt

\begin{tabular}{lccc}
\hline & I & II & III \\
\hline Any $G_{1}$ used LTC & $-0.00525(0.00522)$ & & \\
Any $G_{1}$ used nursing home care & & $-0.0116^{* *}(0.00502)$ & \\
Any $G_{1}$ used informal care & $-0.00179(0.00493)$ & \\
Parent used nursing home care & & $-0.0294^{* * *}(0.00524)$ \\
In-law used nursing home care & & $0.00681(0.00564)$ \\
R provided care to parent & & & $0.0142^{* *}(0.00708)$ \\
Sibling provided care to parent & & $0.00960(0.00631)$ \\
R provided care to in-law & & $0.0116(0.00867)$ \\
Sibling-in-law provided care to R's in-law & & $-0.0171^{* * *}(0.00632)$ \\
\hline Observations & 26,979 & 26,979 & 26,979 \\
\hline
\end{tabular}

NOTES: R denotes the HRS respondent. Marginal effects are shown and the standard errors of those marginal effects are in parentheses. Standard errors are clustered at the individual level. Significance levels:

* $p<0.1$,

**

$p<0.05$,

*** $p<0.01$ 


\section{Table 4}

\section{Long-Term Care Insurance Purchase}

\begin{tabular}{lccc}
\hline & I & II & III \\
\hline Any $G_{1}$ used LTC & $0.00302(0.00315)$ & & \\
Any $G_{1}$ used nursing home care & & $0.00884^{* * *}(0.00299)$ & \\
Any $G_{1}$ used informal care & & $-0.00425(0.00297)$ & \\
Parent used nursing home care & & $0.00837^{* * *}(0.00319)$ \\
In-law used nursing home care & & & $0.00631^{*}(0.00326)$ \\
R provided care to parent & & & $-0.00422(0.00429)$ \\
Sibling provided care to parent & & & $-0.000931(0.00401)$ \\
R provided care to in-law & & & $-0.00856(0.00523)$ \\
Sibling-in-law provided care to R's in-law & & & $-0.000329(0.00409)$ \\
Informal care expectations & $0.00591^{* *}(0.00290)$ & $0.00604^{* *}(0.00290)$ & $0.00610^{* *}(0.00290)$ \\
Inheritance expectations & $0.00320(0.00469)$ & $0.00347(0.00469)$ & $0.00399(0.00471)$ \\
\hline Observations & 26,979 & 26,979 & 26,979 \\
\hline
\end{tabular}

NOTES: R denotes the HRS respondent. Marginal effects are shown and the standard errors of those marginal effects are in parentheses. Standard errors are clustered at the individual level. Significance levels:

$$
\begin{aligned}
* & <<0.1, \\
* * & <0.05, \\
& * * * \\
& p<0.01
\end{aligned}
$$


Table 5

Expectation and Long-Term Care Insurance Purchase Results for Top Half of Wealth Distribution

\begin{tabular}{lccc}
\hline & Informal Care Expectations & Inheritance Expectations & LTCI Purchase \\
\hline Parent used nursing home care & $-0.0301^{* *}(0.0118)$ & $-0.0330^{* * *}(0.00795)$ & $0.0121^{* *}(0.00486)$ \\
In-law used nursing home care & $-0.0166(0.0122)$ & $0.00408(0.00813)$ & $0.0103^{* *}(0.00493)$ \\
R provided care to parent & $0.0232(0.0167)$ & $0.00674(0.0105)$ & $-0.00680(0.00656)$ \\
Sibling provided care to parent & $-0.0127(0.0153)$ & $0.0269^{* * *}(0.0101)$ & $0.00239(0.00645)$ \\
R provided care to in-law & $-0.0277(0.0197)$ & $0.0169(0.0124)$ & $-0.0194^{* * *}(0.00735)$ \\
Sibling-in-law provided care to R's in-law & $-0.0152(0.0152)$ & $-0.0121(0.00959)$ & $0.00372(0.00649)$ \\
Informal care expectations & & & $0.00274(0.00463)$ \\
Inheritance expectations & & & $0.0116(0.00704)$ \\
\hline Observations & 13,493 & 13,493 & 13,493 \\
\hline
\end{tabular}

NOTES: R denotes the HRS respondent. Marginal effects are shown and the standard errors of those marginal effects are in parentheses. Standard errors are clustered at the individual level. Significance levels:

$*$

p $<0.1$,

$* *$

$p<0.05$,

$* * *$

$p<0.01$ 